\title{
Hysteretic Behavior of HPC Column-foundation Joint Subjected to Cyclic Horizontal Loads under Constant Axial Compression
}

\author{
Sooyeon SEO \\ Dept. of Architectural Engineering \\ Korea National University of Transportation \\ Chungju, Republic of Korea \\ e-mail: syseo@ut.ac.kr \\ Sangku KIM \\ Dept. of Technology Development \\ Boowon BMS Co., Ltd \\ Chungju, Republic of Korea \\ e-mail: ibmsbar@naver.com

\section{Jongwook LIM} \\ Dept. of Architectural Engineering \\ Korea National University of Transportation \\ Chungju, Republic of Korea \\ e-mail: jongwook6122@naver.com
}

\author{
Seolki KIM \\ Dept. of Architectural Engineering \\ Korea National University of Transportation \\ Chungju, Republic of Korea \\ e-mail: redsox5564@naver.com \\ Sanghyun NOH \\ Dept. of Architectural Engineering \\ Korea National University of Transportation \\ Chungju, Republic of Korea \\ e-mail: nohsang88@naver.com
}

\author{
Geoncheol LEE \\ Dept. of Architectural Engineering \\ Korea National University of Transportation \\ Chungju, Republic of Korea \\ e-mail: gclee@ut.ac.kr
}

\begin{abstract}
This paper presents a test result to find the structural capacity of Hollow-Precast Concrete (HPC) column with Head-Splice Sleeve (HSS) for the connection of bars under horizontal cyclic load. Two Half scaled HPC column specimens were made with the consideration of construction process in site. The difference between the HPC specimens is the location of HSS for bar connection. The location of the first one is in the bottom slab or foundation while the other is above the bottom slab or foundation. Reinforced concrete (RC) column also was made for the comparison. In order to evaluate the hysteretic behavior of the specimens, horizontal cyclic load was applied to the top of specimen under constant axial load. From the test, it was confirmed that the HPC columns with HSS have enough structural capacity that can be emulated to RC column. This means that the HPC column with HSS can be used in the moment resisting frame system.
\end{abstract}

Keywords-structural capacity; hollow-precast concrete column; head-splice sleeve; horizontal cyclic

\section{INTRODUCTION}

For the connection of members in the precast concrete (PC) construction method, mechanical connections are generally used to connect the main bars. The connection by using splice sleeve where a bar is inserted into and fixed by injecting high strength mortar into, is most frequently used in vertical connections in PC construction. However, existing sleeve products result in a long sleeve due to the unclear embedded length. Thus, the bars around the connection become overly dense, and economic efficiency and construction ability are remarkably reduced.
Furthermore, since epoxy adhesive mortar must be injected from the outside, there is the problem of a slightly cumbersome construction process.

Thus, a head splice sleeve (HSS) as shown in Fig. 1 is being developed by Seo et al. [1]. The HSS connects the bar within the sleeve in a state where the sleeve is already filled with high strength mortar, and thus, there is no need for an additional tube to inject epoxy mortar. Furthermore, the anchorage length of the bar can be reduced according to the enhanced bond strength by the embedded head, and thus, the section can be optimized.
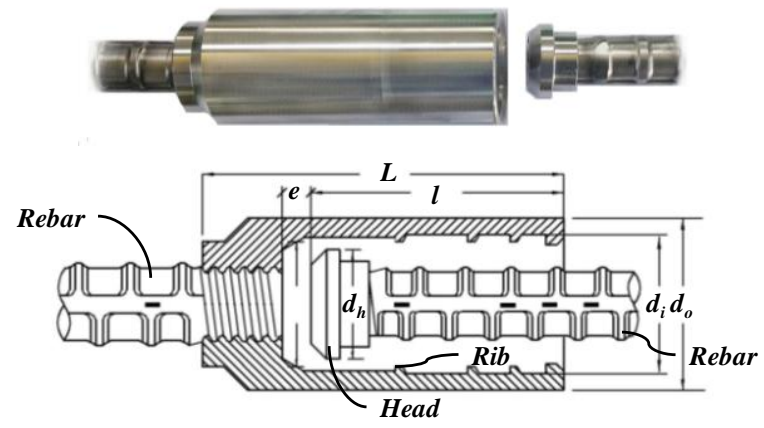

Figure 1. Shape and detail of head-splice sleeve (HSS)

With respect to the structural performance of HSS, Seo et al. [1] performed a series of tensile experiments to evaluate the bond behavior of HSS, and verified that the HSS achieves sufficient tensile performance..

This paper presents an experiment on the hollowed precast concrete (HPC) whose main bars are connected by 
HSS. In addition, a test result about RC specimen is going to be presented for the comparison. In PC specimens, location of connection for construction ability is considered as a variable.

\section{PLAN OF EXPERIMENT}

\section{A. Specimen Design}

The specimens planned to be used in this study are an integrally placed RC specimen and HPC-B and HPC-P specimens whose main bars of D25 are connected by using HSS at the joint between foundation and HPC column as shown in Table 1 and Fig.2.

TABLE I. SPECIMEN LIST

\begin{tabular}{|c|c|c|c|}
\hline $\begin{array}{c}\text { Specimen } \\
\text { name }\end{array}$ & $\begin{array}{c}\text { Location of } \\
\text { HSS }\end{array}$ & $\begin{array}{c}\text { Hollow } \\
\text { diameter (mm) }\end{array}$ & $\begin{array}{c}\text { Connecting } \\
\text { method of bars }\end{array}$ \\
\hline RC & None & None & Lap splicing \\
\hline HPC-B & $\begin{array}{c}\text { Inside } \\
\text { foundation }\end{array}$ & 350 & HSS \\
\hline HPC-P & $\begin{array}{c}\text { Above } \\
\text { foundation }\end{array}$ & 350 & HSS \\
\hline
\end{tabular}

The head splice sleeve embedded within the foundation has been connected with the main bar on the bottom of the HPC column in the HPC-B specimen, and the head splice sleeve was connected to the main bar on the bottom of the HPC column by protruding the sleeve above the foundation in the HPC-P specimen. The bar space of all specimens and the lap spliced length of the RC specimen was designed by the Concrete Design Code [2]. The cross section dimensions of the foundation and columns of the specimens were 1000 $\mathrm{mm} \times 1200 \mathrm{~mm}$ and $450 \mathrm{~mm}$ x $450 \mathrm{~mm}$, respectively. The foundation of all specimens arranged joint transverse reinforcements of D13@150 within the foundation and a bottom bar of D19, and the column bar arranged a main bar of D25-8EA and a hoop of D13@100.

\section{B. Experiment Method}

As displayed in Fig.3, the foundation of the specimen was fixed on the floor and the horizontal slip was prevented by installing screw jacks on either side. The maximum stress level applied to the lowest floor of the building, which is $10 \%$ of axial strength, was applied to the top of column. $410 \mathrm{kN}$ of axial force was applied on the RC specimen and the HPC-P specimen while $620 \mathrm{kN}$ on the HPC-B specimen. In order for the axial force to be consistent even if the lateral displacement increases, an oil jack has been installed between specimen and a frame which can move horizontal 1 direction corresponding to the actuator' stroke. To prevent the splitting failure of column at the top, the top area of column was confined by FRP sheet. Furthermore, in order to eliminate the effect of the actuator's self weight, a pulley was used to install a weight on the center of the specimen and the actuator.

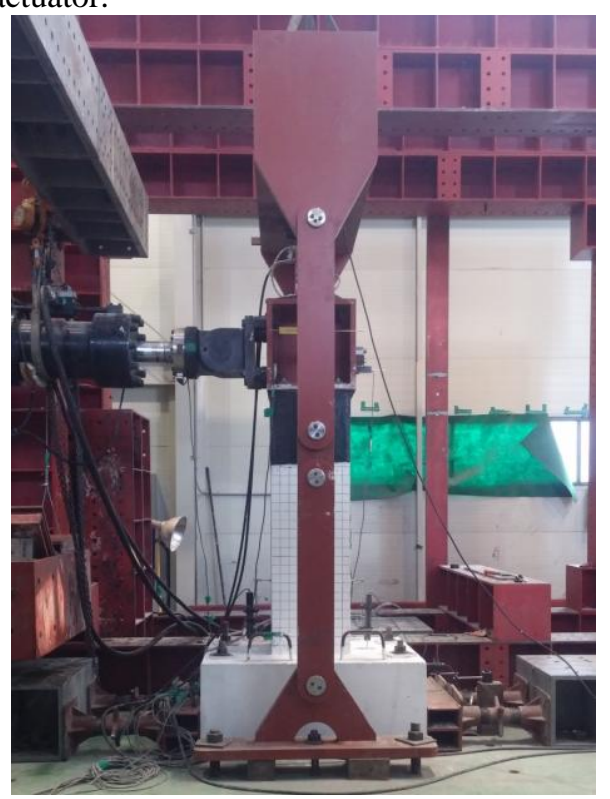

Figure 3. Test set up

Based on the ACI 374 report [3], loading history was designed as shown in Fig.4. Repeated load was applied in two cycles at each phase.
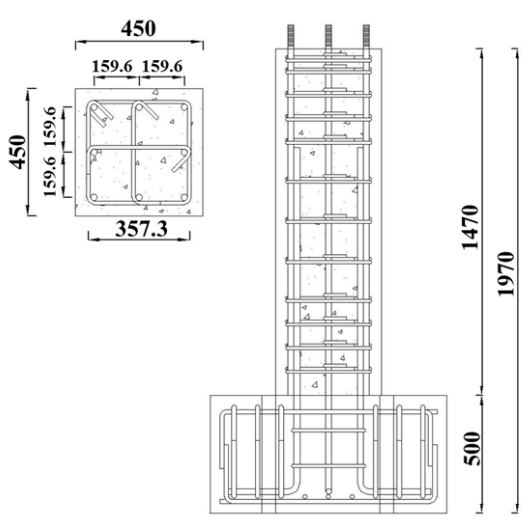

(a) RC (unit: $\mathrm{mm}$ )

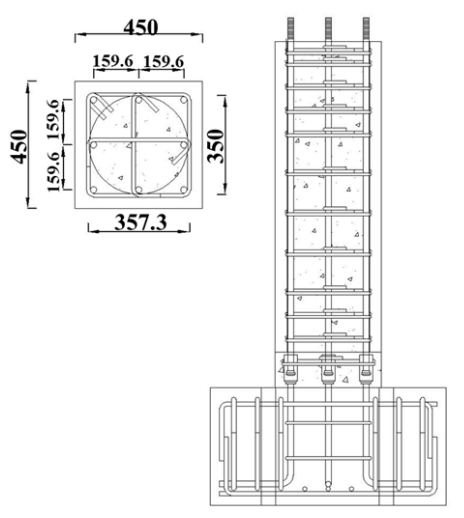

(b) HPC-B (unit: mm)

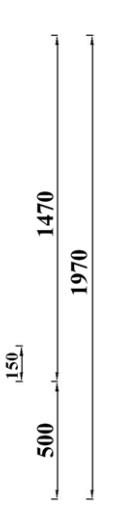

Figure 2. Detail of specimens

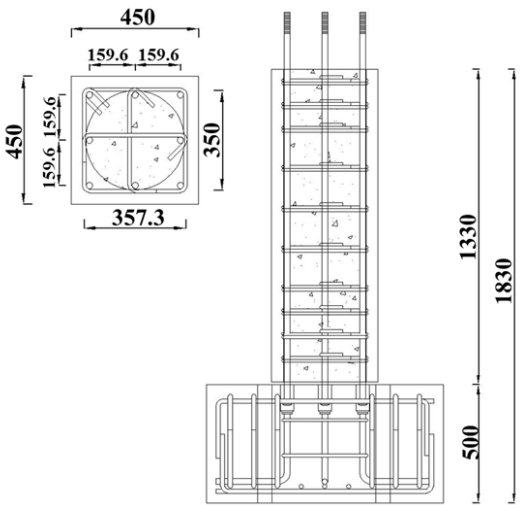

(c) HPC-P (unit: mm) 


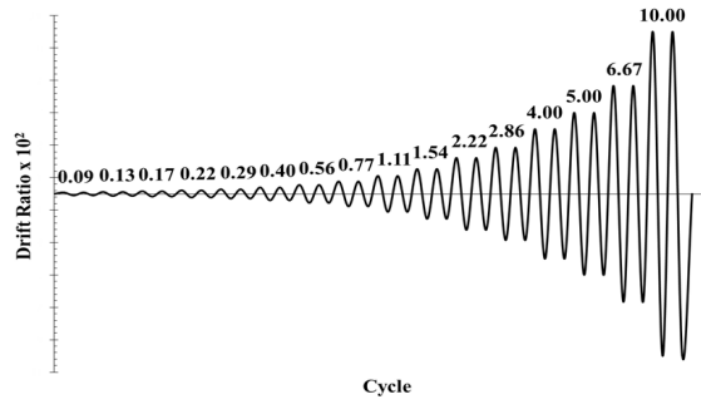

Figure 4. Drift history for horizontal cyclic loading

\section{RESULT AND ANALYSIS}

\section{A. Crack and Failure Shape}

Fig.5 displays the crack and failure shape of each specimen. All specimens commonly displayed a flexural crack, followed by a gradual expansion into the upper part of the column, and a shear crack, followed by breaking away of concrete in the lower part of the column, which eventually led to final failure. With respect to the $\mathrm{RC}$ specimen, an initial flexural crack occurred at drift ratio of $0.10 \%$, and an initial shear crack occurred at drift ratio of $0.29 \%$. At $2.86 \%$, concrete on the lower part of the column chipped off; at $4.00 \%$, the maximum load was reached; and at $7.10 \%$, the experiment was terminated. With respect to the HPC-B specimen, an initial flexural crack occurred at drift ratio of $0.12 \%$, and an initial shear crack occurred at drift ratio of $0.29 \%$. The maximum load was reached at $5.00 \%$; concrete on the lower part of the column initially broken away at $5.09 \%$; and the experiment was terminated at $6.71 \%$. With respect to the HPC-P specimen, an initial flexural crack occurred at drift ratio of $0.09 \%$, and an initial shear crack occurred at drift ratio of $0.56 \%$. Concrete on the lower part of the column initially broken away at drift ratio of $2.22 \%$; the maximum load was reached at $4.00 \%$; and the experiment was terminated at $6.67 \%$.

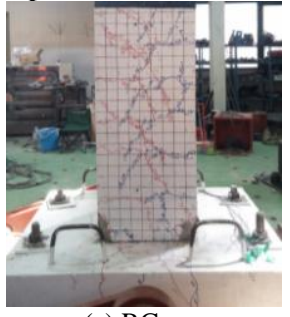

(a) $\mathrm{RC}$

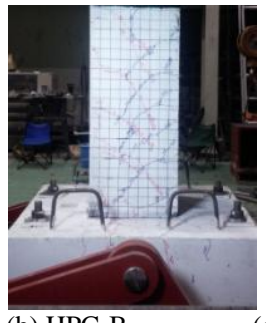

(b) HPC-B

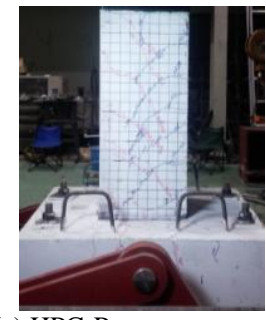

(c) HPC-P
Figure 5. Crack and failure shape

\section{B. Load-drift Curve}

Fig.6 displays a load-drift graph of each specimen. All specimens have enough drift which are more than $5 \%$ at both positive and negative direction. RC specimen and the HPC-P specimen subjected to same axial force displayed maximum load at similar drift ratios and it can be said that overall hysteretic curve shape is very similar each other even though the strength and ductility of RC specimen has

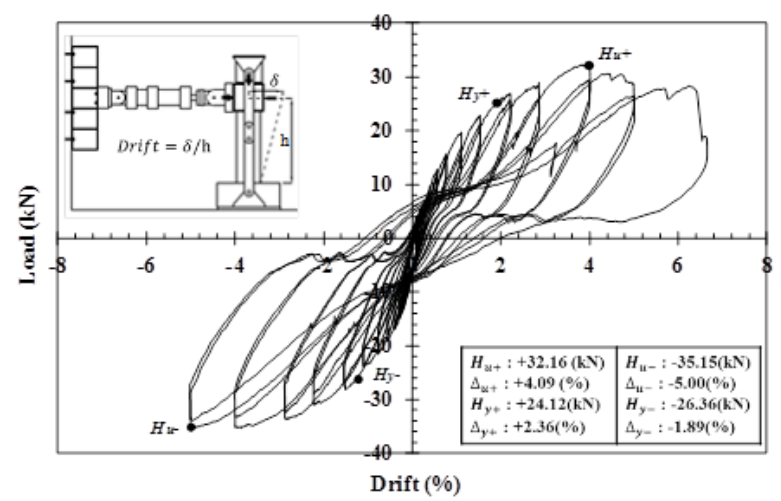

(a) $\mathrm{RC}$

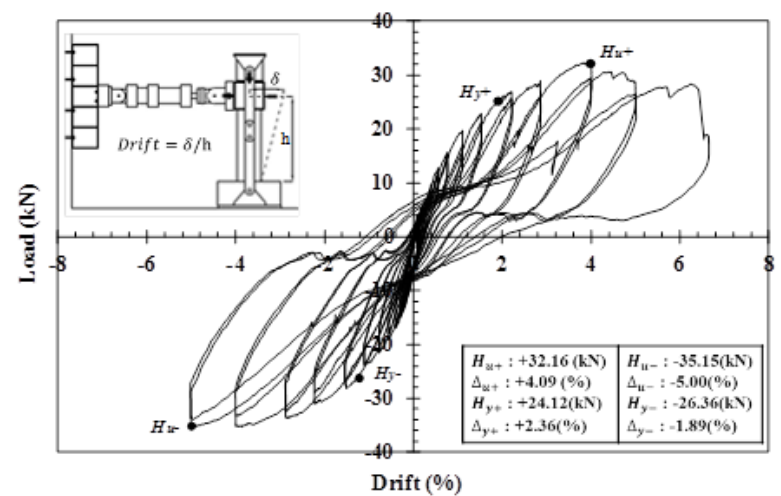

(b) HPC-B

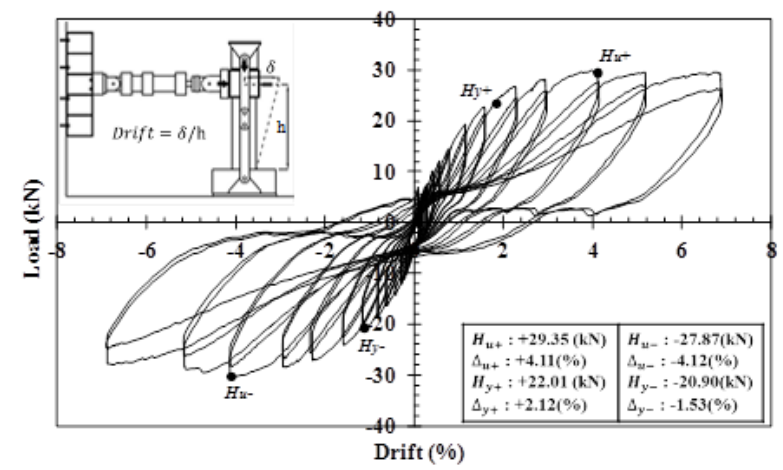

(c) HPC-P

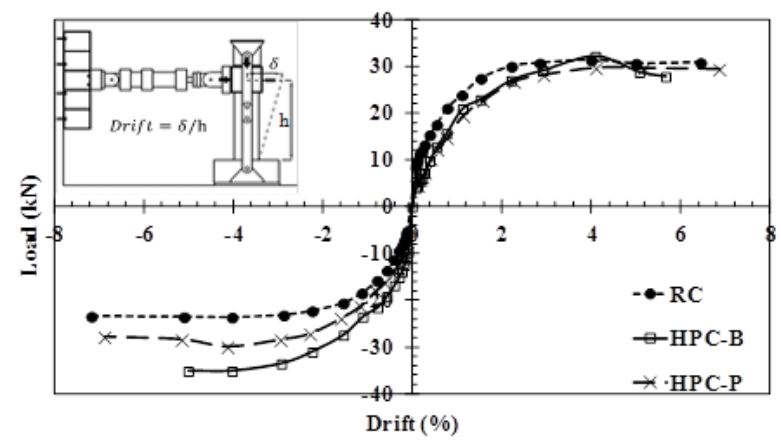

(d) Envelop curves

Figure 6. Load-drift curves 
slightly superior than HPC-P specimen. HPC-B specimen subjected to high axial load due to high concrete strength represents relatively higher yield and ultimate strength than other specimens. But the strength beyond the ultimate state suddenly decreased. In PC specimens, there is more severe pinching phenomenon than RC specimen.

Fig.6(d) displays envelope curve demonstrating the maximum load and displacement point at each step. Upon review of this curve, all specimens displayed similar behavior at positive loading. When negative force was applied, HPC-B specimen displayed the highest ultimate strength while RC specimen displayed the lowest one. Overall load-drift curves represent that HPC columns with HSS as a mechanical connection are considered to have a suitable structural capacity compatible to lap splicing.

\section{Dissipated Energy}

The dissipated energies of specimens at each cycle are accumulated and compared with each other as shown in Fig.7. HPC-B specimen displayed a greater accumulated energy dissipation capacity than the other specimens, which is considered to be based on obtaining high strength when the sleeve is buried in foundation. HPC-P specimen has little bit higher strength at negative loading than $\mathrm{RC}$ specimen so that its dissipated energy is little bit higher than $\mathrm{RC}$ specimen although the pinching is relatively serious.

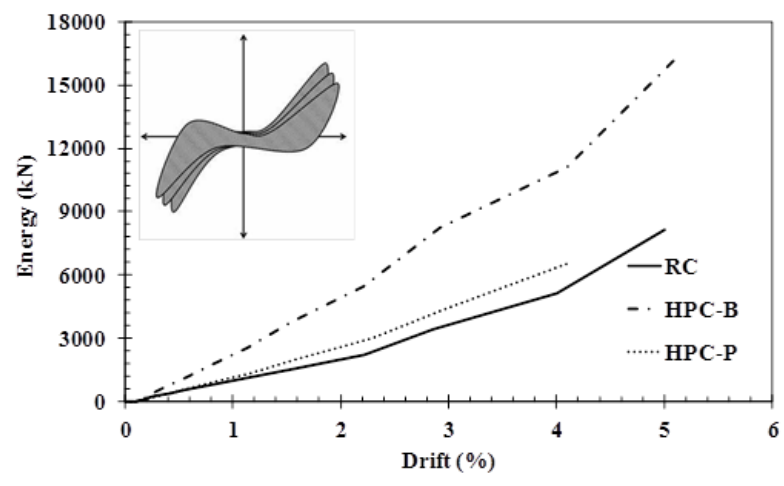

Figure 7. Dissipated energy variation

The strength and drift when the specimens reach to yield and ultimate state are presented in Table 2. Also the ductility and calculated design strength are involved in the table. With respect to ductility ratio $\left(D_{u} / D_{y}\right)$ for ultimate state, RC specimen displayed 2.78 and 2.70 in the positive and negative directions, respectively. However HPC-B and HPC-P specimen showed 1.73 and 1.94 upon positive loading, respectively, which are less than 2 . On the failure state, a failure of frame is generally defined as the strength decreases up to $75 \%$ of ultimate one beyond the ultimate state. If the ductility at failure state is evaluated on the base of above criteria, PC specimens did not reach their failure state and has sufficient ductility, more than 5.

TABLE II. TEST RESULT

\begin{tabular}{|c|c|c|c|c|c|c|c|c|c|}
\hline \multirow{2}{*}{\multicolumn{2}{|c|}{$\begin{array}{c}\text { Specimen } \\
\text { name }\end{array}$}} & \multicolumn{6}{|c|}{ Test result } & \multirow[b]{2}{*}{$\begin{array}{c}H_{n} \\
(\mathrm{kN})\end{array}$} & \multirow[b]{2}{*}{$\frac{H_{u}}{H_{n}}$} \\
\hline & & $\begin{array}{c}H_{y} \\
(\mathrm{kN})\end{array}$ & $\begin{array}{l}D_{y} \\
(\%)\end{array}$ & $\begin{array}{c}H_{u} \\
(\mathrm{kN})\end{array}$ & $\begin{array}{l}D_{u} \\
(\%)\end{array}$ & $\frac{D_{u}}{D_{y}}$ & $H_{f}$ & & \\
\hline \multirow{2}{*}{ RC } & + & 23.5 & 1.4 & 31.3 & 4.0 & 2.8 & 23.5 & \multirow{2}{*}{22.2} & 1.4 \\
\hline & - & 17.7 & 1.5 & 23.7 & 4.0 & 2.7 & 17.8 & & 1.1 \\
\hline \multirow{2}{*}{ HPC-B } & + & 24.1 & 2.4 & 32.8 & 4.1 & 1.7 & 24.6 & \multirow{2}{*}{24.7} & 1.3 \\
\hline & - & 26.4 & 1.9 & 35.2 & 5.0 & 2.7 & 26.4 & & 1.4 \\
\hline \multirow{2}{*}{ HPC-P } & + & 22.0 & 2.1 & 29.4 & 4.1 & 1.9 & 22.1 & \multirow{2}{*}{24.7} & 1.2 \\
\hline & - & 20.9 & 1.5 & 27.9 & 4.1 & 2.7 & 20.9 & & 1.1 \\
\hline
\end{tabular}

\section{CONCLUSION}

In this paper, an experimental result was presented to study the hysteretic behavior of hollow-precast concrete column whose main bars are connected by head-splice sleeve. In addition, a reinforced concrete column was involved in the experiment for the comparison. In order to evaluate the hysteretic behavior of the columns, a horizontal cyclic loading was applied to the specimens under constant axial compression.

Test result revealed that the HPC columns with HSS for bar connection have suitable structural capacity to resist cyclic horizontal load. The HPC column with HSS connection represented higher strength than RC column with lap splicing connection while ductility of those was slightly less than that of RC. Upon evaluation of the energy dissipation capacity and stiffness, the HPC column with HSS has enough capacity exceeding that of RC column. This means that the HPC column with HSS can be used in the moment resisting frame system.

\section{ACKNOWLEDGMENT}

This work was supported by the Human Resource Training Program for Regional Innovation and Creativity through the Ministry of Education and National Research Foundation of Korea (NRF-2015H1C1A1035953).

\section{REFERENCES}

[1] S. Y. Seo, B. R. Nam and S. K. Kim, "Tensile Strength of the Groutfilled Head-Splice-Sleeve", Construction \& Building Materials, submitted.

[2] Korea Concrete Institute, "Concrete Design Code and Commentary", 2012.

[3] ACI Committee 374, "Acceptance Criteria for Moment Frames Based on Structural Testing and Commentary," ACI 374.1-05, American Concrete Institute, 2005, pp. 1-9. 